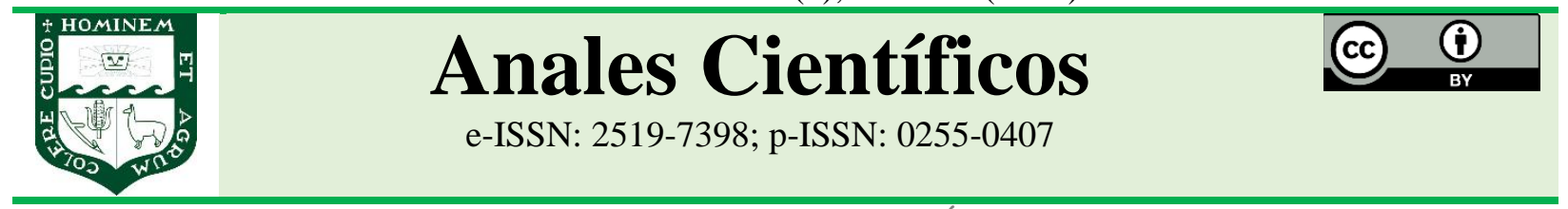

ARTÍCULO ORIGINAL - RESEARCH ARTICLE

http://dx.doi.org/10.21704/ac.v82i2.1787

\title{
ELABORACIÓN DE UN HIDROLIZADO DE PROTEÍNA DE ANCHOVETA (Engraulis ringens) EN POLVO
}

\section{Elaboration of a powdered anchovy protein hydrolyzate (Engraulis ringens)}

\author{
David Roldán A. ${ }^{1 *(D)}$; JR Omote-Sibina ${ }^{1 *}$; ; Andrés Molleda O. ${ }^{1 *}$ \\ ${ }^{1}$ Facultad de Pesquería, Universidad Nacional Agraria La Molina. Av. La Molina s/n, 15024, Lima, Perú. \\ *E-mail: romote@lamolina.edu.pe
}

Recibido: 12/07/2021; Aceptado: 08/12/2021; Publicado: 31/12/2021

\begin{abstract}
The aim of this work was to obtain a protein powder hydrolyzate using headless and gutted anchovy (HG) and its sensory, physicochemical and microbiological characteristics were determined. In the hydrolysis process, seven commercial proteases were evaluated. The hydrolytic activity of the proteases was evaluated using the values of Brix degrees not corrected ( ${ }^{\circ} \mathrm{Bx}$ ref.) and degree of hydrolysis). ( $\mathrm{GH} \%$ ) The experimental procedure to obtain the powdered hydrolyzate was: reception of HG anchovy, washed, ground, weighed and mixed, addition of protease and water, hydrolyzed with stirring, filtered, centrifuged, dehydrated, packed and stored. The commercial proteases that presented the highest GH \% over anchovy proteins were Protex 6L and Protamex with Flavourzyme 1000L. The doses of Protamex $0.2 \%$ and Flavourzyme 1000L of $0.4 \%$ respectively, in relation to the weight of the raw material, reached the highest values of ${ }^{\circ} \mathrm{Bx}$ ref. (11.50) and $\mathrm{GH} \%$ (39.0\%) at 2 hours of processing, The powdered anchovy protein hydrolyzate presented a powdery texture and soft to the touch, beige in color with light tones. The taste and smell were light of fish. Presented 77.13\% of protein, $10.727 \mathrm{~g}$ of lysine / 100 of product and the low microbial load confirmed the adequate sanitary conditions in its elaboration.
\end{abstract}

Keywords. anchovy | hydrolysis | hydrolyzed powder | proteases

\section{RESUMEN}

El objetivo del trabajo fue elaborar un hidrolizado de proteína en polvo utilizando anchoveta sin cabeza y eviscerado (HG) y determinar sus características sensoriales, físico-químicos y microbiológicos. En el proceso de hidrólisis se evaluaron siete proteasas comerciales. La actividad hidrolítica de las proteasas fue evaluada utilizando los valores de grados Brix no corregido ( ${ }^{\circ} \mathrm{Bx}$ ref.) y grado de hidrólisis $(\mathrm{GH} \%)$. El flujo experimental para elaborar el hidrolizado en polvo fue: recepción de anchoveta HG, lavado, molido, pesado y mezclado, adición de proteasa y agua, hidrolizado con agitación, filtrado, centrifugado, deshidratado, envasado y almacenado. Las proteasas comerciales que presentaron mayor GH\% sobre las proteínas de anchoveta fueron Protex $6 \mathrm{~L}$ y Protamex con Flavourzyme 1000L. Las dosis de Protamex 0,2 \% y Flavourzyme 1000L de 0,4 \% respectivamente, en relación al peso de la materia prima, alcanzaron los mayores valores de ${ }^{\circ} \mathrm{Bx}$ ref. $(11,50)$ y GH\% $(39,0 \%)$ a las 2 horas de proceso. El hidrolizado de proteínas de anchoveta en polvo presentó textura de polvo y suave al tacto, de color 
beige con tonos claros. El sabor y olor fueron ligeros a pescado. Presentó 77,13 \% de proteína, 10,727 g de lisina/100 de producto y la baja carga microbiana confirmo las adecuadas condiciones sanitarias en su elaboración.

Palabras clave: anchoveta | hidrolisis | hidrolizado en polvo | proteasas

\section{Forma de citar el artículo (Formato APA):}

Roldán, D., Omote-Sibina, J.R., \& Molleda, A. (2021). Elaboración de un hidrolizado de proteína de anchoveta (Engraulis ringens) en polvo. Anales Científicos. 81(2), 251-261. http://dx.doi.org/10.21704/ac.v82i2.1787

Autor de correspondencia (*): J.R. Omote-Sibina. Email: romote@ lamolina.edu.pe

(c) Los autores. Publicado por la Universidad Nacional Agraria La Molina.

This is an open access article under the CC BY

\section{INTRODUCCIÓN}

La anchoveta (Engraulis ringens) valorada desde las culturas prehispánicas por su elevado valor nutricional, es el recurso hidrobiológico más pescado en el mundo y la principal especie de la actividad pesquera del Perú (PRODUCE, 2018). Factores que disminuyen su frescura como la elevada captura, inadecuado almacenamiento en las embarcaciones, entre otros ocasionan la continuidad de la utilización de anchoveta en la producción de harina para la formulación de alimentos para consumo animal (Maza et al., 2016). Por otro lado, el desvío de anchoveta destinada al consumo humano directo (CHD), por la flota artesanal, para la producción de harina de pescado es una problemática que inhibe la innovación, genera graves perjuicios para la economía y la sostenibilidad del recurso (Grillo et al., 2019). Ante ello, la utilización de los nutrientes de este recurso hidrobiológico en la preparación de productos para consumo humano directo (CHD) es constante motivo de investigación. Más aún si se reconoce que la anchoveta es un alimento proteico rico en Lisina, aminoácido imprescindible para el crecimiento de los niños y es considerada una gran fuente de ácidos grasos omega 3 que favorecen la interconexión nerviosa en el cerebro y protege el sistema cardiovascular (ANDINA, 2020).

Hleap y Gutiérrez (2017) mencionan que el proceso de hidrólisis permite el procesamiento integral del pescado, por ello existe gran interés en su desarrollo por las industrias de todo el mundo con la utilización de nuevas especies, procesos y tecnologías. El hidrolizado de pescado se define como proteínas de pescado que se han fraccionado en péptidos de diferentes tamaños (He et al., 2013). Alegre (2015) menciona que el efecto de que la proteína sea parcial o totalmente hidrolizada al consumirla da lugar a que ésta se aproveche mejor, al brindar los nutrientes esenciales al organismo.

En un proceso enzimático, el pescado se convierte en ingredientes alimentarios de valor, tales como, concentrados proteicos del tipo A y B para consumo humano directo, aceite que presenta un alto contenido de ácido grasos poliinsaturados como EPA (Ácido eicosapentaenoico) y DHA (Ácido docosahexaenoico), y también se obtiene una fracción de hueso limpio, adecuado para la obtención de colágeno (Morales-Medina et al., 2017). Algunos estudios sobre hidrolizados de pescado son los realizados por Oliveira et al., 2016 (Thunnus albacares), García-Moreno et al., (2016) (Sardine pilchardus) y Sifuentes-Penagos et al. (2018). (Engraulis ringens).

La hidrólisis enzimática es un método alternativo, que permite la recuperación de proteínas del pescado a través del empleo de enzimas proteolíticas que solubilización la proteína, resultando en dos fracciones: soluble e insoluble. La fracción insoluble se puede utilizar en la alimentación animal y la fracción soluble, que contiene la proteína hidrolizada, puede constituirse como ingrediente para ser incorporada en los alimentos elaborados y destinados para consumo humano (Sifuentes-Penagos et al., 2018).

Hleap y Gutiérrez (2017) reportan que las enzimas de tipo proteolítico (proteasa) pueden ser utilizadas como catalizadoras del proceso de hidrólisis, además de la ruptura de los enlaces peptídicos generan otros 
beneficios al producto final que pueden ser para la tecnología de alimentos, la salud o la alimentación.

Los objetivos del estudio fueron elaborar un hidrolizado de proteína de anchoveta HG en polvo y determinar sus características sensoriales, físicoquímicas y microbiológicas.

\section{MATERIALES Y MÉTODOS}

Se utilizó una muestra de $30 \mathrm{~kg}$ de anchoveta $\mathrm{HG}$ congelada y envasada en bolsas de polipropileno de 0.5 $\mathrm{kg}$. Fueron almacenadas durante el estudio en condiciones de congelación a $-18 \pm 1^{\circ} \mathrm{C}$ (Congeladora Electrolux. Suecia). En la hidrólisis de las proteínas de anchoveta $\mathrm{HG}$, se utilizaron siete enzimas comerciales del tipo (1) Endopeptidasa: Corolase 7089, Corolase Hp, Corolase L10, Protex 6L Dresenzyme y Protamex: y (2) Exopeptidasa: Flavourzyme 1000L. En el proceso de hidrólisis las proteasas fueron evaluadas de forma individual (ensayos $\mathrm{H}_{1}, \mathrm{H}_{2}, \mathrm{H}_{3}, \mathrm{H}_{4}$ y $\mathrm{H}_{5}$ ). Sólo en el ensayo $\mathrm{H}_{6}$, se utilizó inicialmente Protamex y después Flavourzyme 1000L. La tabla 1 muestra los parámetros del proceso de hidrólisis utilizados para las diferentes proteasas.

El pH óptimo para cada proteasa, alcalino o ácido, fue alcanzado con adiciones de solución de $\mathrm{NaOH}$ al 0,1 N y $\mathrm{HCl} 0,1 \mathrm{~N}$, respectivamente. La anchoveta $\mathrm{HG}$ utilizada fue descongelada, pesada y medida. La frescura fue determinada según tabla de evaluación sensorial (SANIPES, 2010). La medición del pH fue directa sobre la mezcla pescado-agua-enzima ( $\mathrm{pH}-$ meter Hanna, modelo HI 8424, Italia). La determinación del grado Brix no corregido ( ${ }^{\circ} \mathrm{Bx}$ ref.) fue directa a temperatura ambiental $\left(21 \pm 1^{\circ} \mathrm{C}\right.$ ) (Sugar Refractometer model RHB rango 0 - $80{ }^{\circ}$ Brix,
Alemania). El grado Brix es un indicador que mide la cantidad de sólidos solubles presentes en el alimento expresados en porcentaje de sacarosa. Los hidrolizados de alimentos presentan una determinada cantidad de sólidos soluble que se incrementa conforme se hidroliza la proteína, por ello al no medir sólo azúcar, la lectura del refractómetro se denomina medición de grado Brix no corregido ( ${ }^{\circ} \mathrm{Bx}$ ref.) (KRÜSS, 2020).

El grado de hidrólisis (GH\%) se determinó siguiendo el procedimiento de Dumay et al. (2003). Para evaluar las proteasas y elaborar el hidrolizado de proteína de anchoveta, se utilizó el procedimiento reportado por He et al. (2013), con modificaciones. La anchoveta HG se descongeló en refrigeración a $5 \pm 1{ }^{\circ} \mathrm{C}$ (Refrigerador General Electric, USA) 12 horas antes al proceso de hidrolisis; después fue pesada, molida en moledora de carne (marca Berkel, USA) y mezclada con agua (relación 1:1), posteriormente se calentó a $85{ }^{\circ} \mathrm{C}$ por 10 minutos para inactivaron las enzimas endógenas a fin de investigar el efecto de las proteasas comerciales.

La mezcla obtenida se enfrió hasta la temperatura óptima recomendada para cada proteasa (Tabla 1) y se inició la hidrólisis proteolítica, (Sifuentes-Penagos et al., 2018). Para la hidrólisis se utilizó un Baño maría con agitación (modelo 1092 GFL, Alemania), con soporte para seis matraces de $1 \mathrm{~L}$, se trabajó $750 \mathrm{~mL}$ y una velocidad de agitación de $100 \mathrm{rpm}$. Durante la hidrólisis se midió el valor $\mathrm{pH}$ y temperatura (Termómetro digital marca CPS, modelo TM50, USA); terminado el hidrolizado se inactivaron las enzimas por calentamiento a $85 \pm 1{ }^{\circ} \mathrm{C}$ por 10 minutos (Novozymes A/S, 1998).

Tabla 1. Parámetros del proceso de hidrólisis con las proteasas comerciales.

\begin{tabular}{clcccccc}
\hline No & Proteasa comercial & Dosis $(\%)$ & pH & T $\left({ }^{\circ} \mathbf{C}\right)$ & t (min) & Agua:sustrato & Tratamiento \\
\hline 1 & Corolase 7089 & $0,25^{*}$ & 7,5 & 50 & 120 & $1: 1$ & $\mathrm{H} 1$ \\
2 & Corolase H-pH & $0,50^{*}$ & 8,5 & 50 & 120 & $1: 1$ & $\mathrm{H} 2$ \\
3 & Corolase L10 & $0,25^{*}$ & 7,0 & 60 & 120 & $1: 1$. & $\mathrm{H} 3$ \\
4 & Protex 6L & $0,50^{*}$ & 6,5 & 60 & 120 & $1: 1$ & $\mathrm{H} 4$ \\
5 & Dresenzyme & $0,25^{* *}$ & 7,0 & 60 & 120 & $1: 1$ & $\mathrm{H} 5$ \\
6 & Protamex & $0,20^{\wedge}$ & 7,5 & 55 & 120 & & $\mathrm{H} 6$ \\
7 & Flavourzime & $0,40^{\wedge}$ & 6,0 & 50 & 120 & & $\mathrm{H} 6$ \\
\hline * En función del contenido de proteína & & & & & & \\
** En función de sólidos totales & & & & & &
\end{tabular}


La mezcla hidrolizada fue filtrada, la fase liquida hidrolizada fue centrifugada para recuperar el hidrolizado y aceite de anchoveta (Centrífuga International, USA). El hidrolizado fue deshidratado por aspersión con temperaturas de ingreso y salida de $180{ }^{\circ} \mathrm{C}$ y $92{ }^{\circ} \mathrm{C}$, respectivamente (Atomizador Lab Plant, modelo SD-Basic, España). El hidrolizado de anchoveta HG en polvo fue envasado en bolsa de polipropileno opaco y se almacenó en condiciones ambientales.

Los resultados del GH\%, de los ensayos experimentales, fueron sometidos a la prueba estadística DCA (Diseño completamente al azar) y la prueba de Tukey para comparar los ensayos de la presente investigación. Todos los análisis se hicieron por medio del Statistical Analysis Software (SAS/STAT, 2019).

Las muestras de los hidrolizados de anchoveta en polvo fueron sometidas a una prueba de preferencia utilizando un panel semientrenado de 15 personas. Se utilizó el método no paramétrico de Friedman. Para el sabor, la muestra de hidrolizado en polvo fue diluida utilizando el contenido de una cucharita $(3,0 \mathrm{~g})$ en una taza con $80 \mathrm{ml}$ de agua caliente.

\section{Características de la anchoveta HG}

La anchoveta HG descongelada presentó buen grado de conservación con características de buena textura y olor típico a pescado fresco. Presentó longitud estándar de 11,5 $\pm 0,3 \mathrm{~cm}$ (longitud total 13,7 $\pm 0.3 \mathrm{~cm}$ ) y peso de $13,78 \pm 0,2$ g. La anchoveta HG descongelada alcanzó categoría de frescura B (SANIPES, 2010). Así mismo, el peso y tamaño de la anchoveta HG fueron de ejemplares adultos y de tamaño comercial según PRODUCE (2019). La tabla 2 muestra los resultados de la composición química proximal de la anchoveta $\mathrm{HG}$ descongelada obtenida en el presenta trabajo y de otros autores.

La variación que presentan los resultados obtenidos en comparación a los reportados por los otros autores fue atribuida a que la composición química del pescado es influenciada por la edad, sexo, época de año y madurez sexual (Huss, 1999).

\section{Evaluación de las enzimas proteolíticas (proteasas) comerciales}

La tabla 3 muestra los valores de ${ }^{\circ} \mathrm{Bx}$ ref. durante los ensayos del proceso de hidrólisis de la proteína de anchoveta $\mathrm{HG}$ utilizando las diferentes proteasas comerciales $\left(\mathrm{H}_{1}, \mathrm{H}_{2}, \mathrm{H}_{3}, \mathrm{H}_{4}, \mathrm{y} \mathrm{H}_{5}\right)$.

\section{RESULTADOS Y DISCUSIÓN}

Tabla 2. Composición química proximal de anchoveta HG descongelada.

\begin{tabular}{lccc}
\hline \multicolumn{1}{c}{ Ensayo } & Resultado \pm desviación estándar \\
& Experimental & Ordoñez y Hernandez & Sifuentes-Penagos et al. (2018) \\
\hline Humedad & $75,17 \pm 0,11$ & $73,50 \pm 0,01$ & $77,65 \pm 0,15$ \\
Proteína bruta & $17,21 \pm 0,12$ & $18,40 \pm 0,103$ & $13,86 \pm 0,14$ \\
Grasa cruda & $5,63 \pm 0,14$ & $6,99 \pm 0,04$ & $5,24 \pm 0,15$ \\
Ceniza & $1,29 \pm 0,09$ & $1,33 \pm 0,04$ & $2,71 \pm 0,01$ \\
Carbohidratos & $0,70 \pm 0,46$ & - & - \\
\hline
\end{tabular}

Tabla 3. Lectura de ${ }^{\circ} \mathrm{Bx}$ ref. durante la hidrólisis de anchoveta según ensayos.

\begin{tabular}{cccccc}
\hline $\begin{array}{c}\mathbf{t} \\
(\mathbf{m i n})\end{array}$ & $\mathbf{H 1}$ & $\mathbf{H 2}$ & Tratamientos & $\mathbf{H 4}$ & $\mathbf{H 5}$ \\
\hline 0 & $6,50 \pm 0,2$ & $7,30 \pm 0,1$ & $5,30 \pm 0,2$ & $7,30 \pm 0,2$ & $6,00 \pm 0,1$ \\
15 & $8,37 \pm 0,1$ & $9,00 \pm 0,2$ & $7,00 \pm 0,2$ & $9,30 \pm 0,1$ & $6,80 \pm 0,1$ \\
30 & $9,30 \pm 0,2$ & $9,75 \pm 0,2$ & $7,15 \pm 0,1$ & $9,50 \pm 0,2$ & $7,00 \pm 0,2$ \\
45 & $9,60 \pm 0,2$ & $10,00 \pm 0,1$ & $7,35 \pm 0,1$ & $10,30 \pm 0,1$ & $7,20 \pm 0,1$ \\
60 & $9,70 \pm 0,2$ & $10,35 \pm 0,2$ & $7,91 \pm 0,2$ & $10,50 \pm 0,2$ & $7,50 \pm 0,2$ \\
90 & $9,70 \pm 0,1$ & $10,35 \pm 0,1$ & $8,50 \pm 0,2$ & $10,80 \pm 0,2$ & $6,50 \pm 0,1$ \\
120 & $9,70 \pm 0,1$ & $10,35 \pm 0,2$ & $8,50 \pm 0,1$ & $11,00 \pm 0,1$ & $6,50 \pm 0,2$ \\
\hline
\end{tabular}


Los resultados reportados en la tabla 3 indicaron que los ensayos $\mathrm{H}_{1}$ y $\mathrm{H}_{2}$, presentaron aumento del ${ }^{\circ} \mathrm{Bx}$ ref. en los primeros 60 minutos de hidrólisis, después fue constante; los ensayos $\mathrm{H}_{3} \quad$ y $\mathrm{H}_{4}$ presentaron incrementos hasta los 120 minutos. Según el aumento de los ${ }^{\circ} \mathrm{Bx}$ ref. ( ${ }^{\circ} \mathrm{Bx}$ ref. final $-{ }^{\circ} \mathrm{Bx}$ ref. inicial), el ensayo con Dresenzyme $\left(\mathrm{H}_{5}\right)$ presentó la menor actividad hidrolítica sobre las proteínas de anchoveta, mientras que los demás ensayos $\left(\mathrm{H}_{1}, \mathrm{H}_{2}, \mathrm{H}_{3}, \mathrm{y} \mathrm{H}_{4}\right)$ presentaron incrementos entre 2,61 a 3,70. Destaca el ensayo $\mathrm{H}_{4}$ que utilizó Protex $6 \mathrm{~L}$ en $0,5 \%$ respecto al contenido de proteína.

En la figura 1 se observa que las tendencias de los valores del ${ }^{\circ} \mathrm{Bx}$ ref. de los ensayos $\mathrm{H}_{1}, \mathrm{H}_{2}, \mathrm{H}_{3}, \mathrm{y} \mathrm{H}_{4}$ ), durante el proceso de hidrólisis de las proteínas de anchoveta, fueron similares. El ensayo $\mathrm{H}_{5}$, presento una tendencia diferente; ello podría ser atribuido a la toma de las muestras evaluadas, condición de la materia prima o a la reducida actividad de la Dresenzyme, en dichas condiciones.

Opheim et al. (2015) mencionan que no se presentaron diferencias significativas durante el hidrolizado de subproductos de salmón (Salmo salar), al utilizar diferentes enzimas y las propias de los subproductos Sin embargo, el calentamiento a temperaturas superiores a $70^{\circ} \mathrm{C}$ influye negativamente en la obtención de los péptidos, lo que no se presenta a temperaturas $40^{\circ} \mathrm{C}$.

En la tabla 4 se muestra las lecturas del ${ }^{\circ} \mathrm{Bx}$ ref. del ensayo $\mathrm{H}_{6}$, se pudo observar que los ${ }^{\circ} \mathrm{Bx}$ ref. del hidrolizado con Protamex (primera enzima $\mathrm{H}_{6}$ ) se incrementó desde 7,0 hasta 8,62 en sesenta minutos. La adición de enzima Flavourzyme 1000L (segunda enzima $\mathrm{H}_{6}$ ) permitió un incremento de ${ }^{\circ}$ Brix ref. hasta 11,5 en 120 minutos. El aumento de los ${ }^{\circ} \mathrm{Bx}$ ref. durante la hidrólisis fue 4,5; valor muy superior a los medidos en los ensayos $\mathrm{H}_{1}, \mathrm{H}_{2}, \mathrm{H}_{3}, \mathrm{H}_{4}$ y $\mathrm{H}_{5}$. Según los valores del ${ }^{\circ} \mathrm{Bx}$ ref. encontrados, la utilización de Protex 6L y Protamex con Flavourzyme 1000L (ensayos $\mathrm{H}_{4}$ y $\mathrm{H}_{6}$, respectivamente), serían las proteasas que propician mayor fraccionamiento de las proteínas de anchoveta en el proceso de hidrólisis realizado.

Nguyen et al. (2012), utilizando Protamex en subproductos del atún, reportaron obtener hidrolizados de excelente calidad, así mismo, que dicha proteólisis puede ser útil para la producción de dos diferentes fracciones: una con proteínas insolubles y otra rica en péptidos de media a pequeña masa molecular.

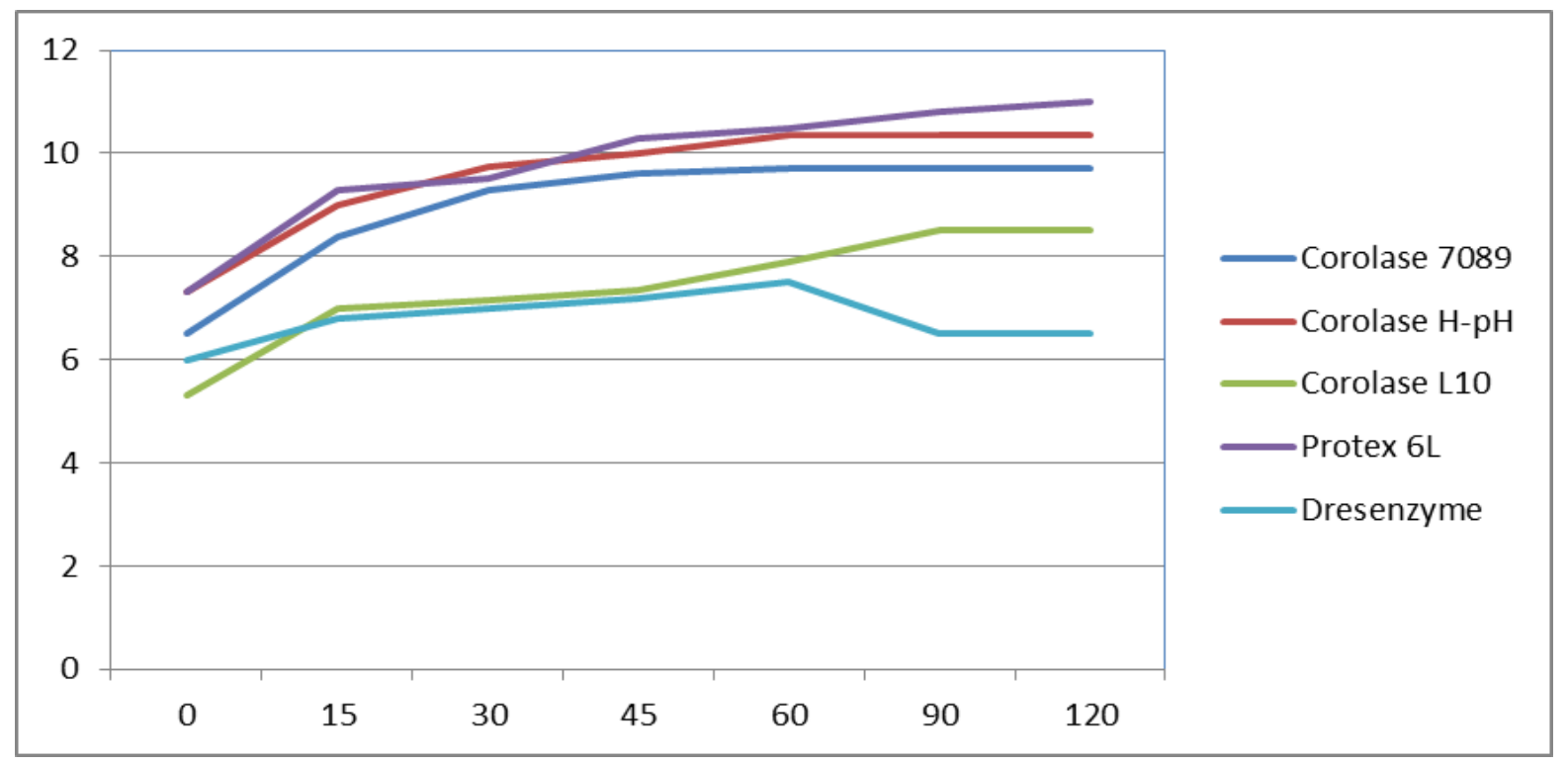

Figura 1. Tendencia de ${ }^{\circ} \mathrm{Bx}$ ref. durante la hidrólisis de los diferentes ensayos. 
Tabla 4. ${ }^{\circ} \mathrm{Bx}$ ref. del tratamiento $\mathrm{H}_{6}$.

\begin{tabular}{ccc}
\hline \multirow{1}{*}{$\begin{array}{c}\text { thoras) } \\
\text { nyy }\end{array}$} & \multicolumn{2}{c}{ Tratamiento H6 } \\
\hline 0 & Protamex & Flavourzyme 1000L \\
15 & $7,00 \pm 0,1$ & - \\
30 & $8,75 \pm 0,2$ & - \\
45 & $8,00 \pm 0,1$ & - \\
60 & $8,37 \pm 0,1$ & - \\
75 & - & - \\
90 & - & $8,70 \pm 0,2$ \\
105 & - & $9,50 \pm 0,2$ \\
120 & - & $10,00 \pm 0,1$ \\
\hline
\end{tabular}

La medición del fraccionamiento de las proteínas según el grado de Hidrólisis (GH\%), solo se determinó en los ensayos de mayor fraccionamiento de la proteína de anchoveta, según valor de ${ }^{\circ} \mathrm{Bx}$ ref. (ensayos $\mathrm{H}_{4}$ y $\mathrm{H}_{6}$ ). Los resultados del $\mathrm{GH} \%$ de los ensayos $\mathrm{H}_{4}$ y $\mathrm{H}_{6}$, realizados después de 120 minutos de hidrolizado, fueron $18.1 \%$ y $39.0 \%$, respectivamente.

La utilización de Protamex 0,2\% y Flavourzyme 1000L $0,4 \%$, respecto al peso de la materia prima (ensayo $\mathrm{H}_{6}$ ), en la hidrólisis de las proteínas de anchoveta presentó el más alto GH\% (39,0\%) a las 2 horas de proceso, lo que permite inducir un elevado grado de desdoblamiento de las proteínas y con ello mayor contenido de péptidos solubles bajo las condiciones experimentales del estudio. Posiblemente sea por la condición de las proteasas utilizadas en este ensayo, al ser enzimas endopeptidasa y exopeptidasa, respectivamente. Sifuentes, et al. (2018) trabajando en hidrólisis de anchoveta con Protamex $(0,7 \mathrm{~kg}$ pescado/ kg agua por $90 \mathrm{~min}$ a $55{ }^{\circ} \mathrm{C}$ y pH de 7,5), reportaron GH\% de 16,917. Así mismo, Pandia et al. (2013) reportan que un hidrolizado proteico de subproductos de anchoveta con $15 \%$ de GH se consiguió utilizando sólo Protamex a $63,93{ }^{\circ} \mathrm{C}$ por $82,91 \mathrm{~min}$ con $1,59 \%$ de enzima y relación agua: sustrato de 0,85 .

Los resultados de los ${ }^{\circ} \mathrm{Bx}$ ref. y $\mathrm{GH} \%$ del ensayo $\mathrm{H}_{6}$ indicaría que la hidrólisis fue mayor con el uso combinado de Protamex seguido de Flavourzyme 1000L en comparación sólo al Protamex. Aldoradín et al. (2013) trabajando con Protamex y Flavorzyme en el proceso de hidrólisis de piel de pota reportaron que la enzima Protamex presentó mayor actividad hidrolítica que Flavourzyme. $\mathrm{Al}$ respecto, se debe indicar que las proteasas son enzimas muy potentes y eficaces, quimicamente son proteínas con un sitio activo de cierta especificidad, es decir existe una enzima para cada aplicación. Por otro lado la diferente especie utilizada con diferente composición quimica tambien haya influido en el resultado obtenido.

$\mathrm{El}{ }^{\circ} \mathrm{Bx}$ ref. es un indicador para medir el proceso de hidrólisis que debe ser confirmado con el GH\%. Se considera que a mayor hidrólisis mayor desdoblamiento de las proteínas y con ello mayor valor de ${ }^{\circ} \mathrm{Bx}$ ref. y GH\%. García et al. (2014), trabando con la subtilisina (serina endopeptidasa) reportan que el contenido de péptidos de menor peso molecular tiene una relación inversamente proporcional con el GH\% del hidrolizado de músculo de sardina. CECOPESCA (2012) reportan que se mejora las propiedades funcionales de los productos alimenticios como la solubilidad, el poder espumante y el emulsificante con un $\mathrm{GH} \%$ bajo, es decir, entre el $1 \%$ y el $10 \%$; por otro lado, un grado extensivo (mayor a 10\%), genera péptidos que tienen elevada solubilidad y presentan mayor absorción gastrointestinal, por ello pueden ser usados para aplicación en alimentos líquidos y para dietas de personas ancianas, deportistas, enfermos hepáticos y dietas hipocalóricas.

Vioque y Millán (2005) agrupan los hidrolizados que se producen para su uso en alimentación en (1) hidrolizados con bajo grado de hidrólisis, entre el $1 \%$ y $10 \%$; para la mejora de las propiedades funcionales y como saborizantes (2) hidrolizados extensivos con grado de hidrólisis superior al $10 \%$, para su uso en alimentación especializada.

Según los resultados obtenidos el hidrolizado de proteínas de anchoveta de ambos ensayos $\left(\mathrm{H}_{4}\right.$ y $\left.\mathrm{H}_{6}\right)$ elaborados a nivel laboratorio, de acuerdo al $\mathrm{GH} \%$, está enmarcado dentro de la clasificación de hidrolizados extensivos.

La deshidratación se realizó en secador por aspersión utilizando los hidrolizados con Protex 6L y Protamex con Flavourzyme 1000L (ensayos $\mathrm{H}_{4} \quad$ y $\mathrm{H}_{6}$, respectivamente), ensayos que presentaron mayor fraccionamiento de las proteínas de anchoveta. 


\section{Características del hidrolizado de anchoveta en polvo}

Respecto a la evaluación sensorial del concentrado de proteína de anchoveta en polvo se pudo observar que ambas muestras presentaron textura de polvo y suave al tacto. El color fue beige con tonos más claros en la muestra del ensayo $\mathrm{H}_{6}$; el olor fue característico a pescado en la muestra del ensayo $\mathrm{H}_{4}$ mientras que la muestra del ensayo $\mathrm{H}_{6}$ presentó olor muy ligero a pescado. Los resultados sensoriales obtenidos fueron similares a los reportados por Pandia et al. (2013) quienes mencionan que el hidrolizado deshidratado de restos de anchoveta fresca presentó olor característico a pescado, sabor a pescado y marisco, color beige y textura pulverulenta fina. Los atributos a pescado del hidrolizado en polvo de anchoveta se pueden disminuir mejorando las características del olor y sabor de la carne de anchoveta, al respeto, se han realizado diversos estudios como el realizado por Maza y Pariona (2020) en el desarrollo de un concentrado húmedo de proteína (surimi).
Los resultados de la prueba de preferencia de las muestras de hidrolizado de anchoveta HG en polvo se presentan en la figura 2. Los resultados estadísticos de la evaluación sensorial indicaron que existe diferencia significativa $(\mathrm{p}<0,05)$ entre las muestras, la muestra de mayor preferencia fue la obtenida del ensayo $\mathrm{H}_{6}$ que utilizó las enzimas Protamex y Flavourzyme 1000L.

La composición química proximal del hidrolizado en polvo (ensayo $\mathrm{H}_{6}$ ), que se reporta en la tabla 5, muestra diferencia respecto a los reportados por Accinelli y López (2013) para concentrado de anchoveta. Sheron et al. (2017) para concentrados de proteína utilizando anchoveta desgrasada; Pandia et al. (2013) para hidrolizado de subproductos de anchoveta liofilizado y Paz et al. (2016) para hidrolizado de subproductos de gamitana deshidratado. Estas diferencias fueron atribuidas a las diferentes materias primas y tecnologías utilizadas para su elaboración.

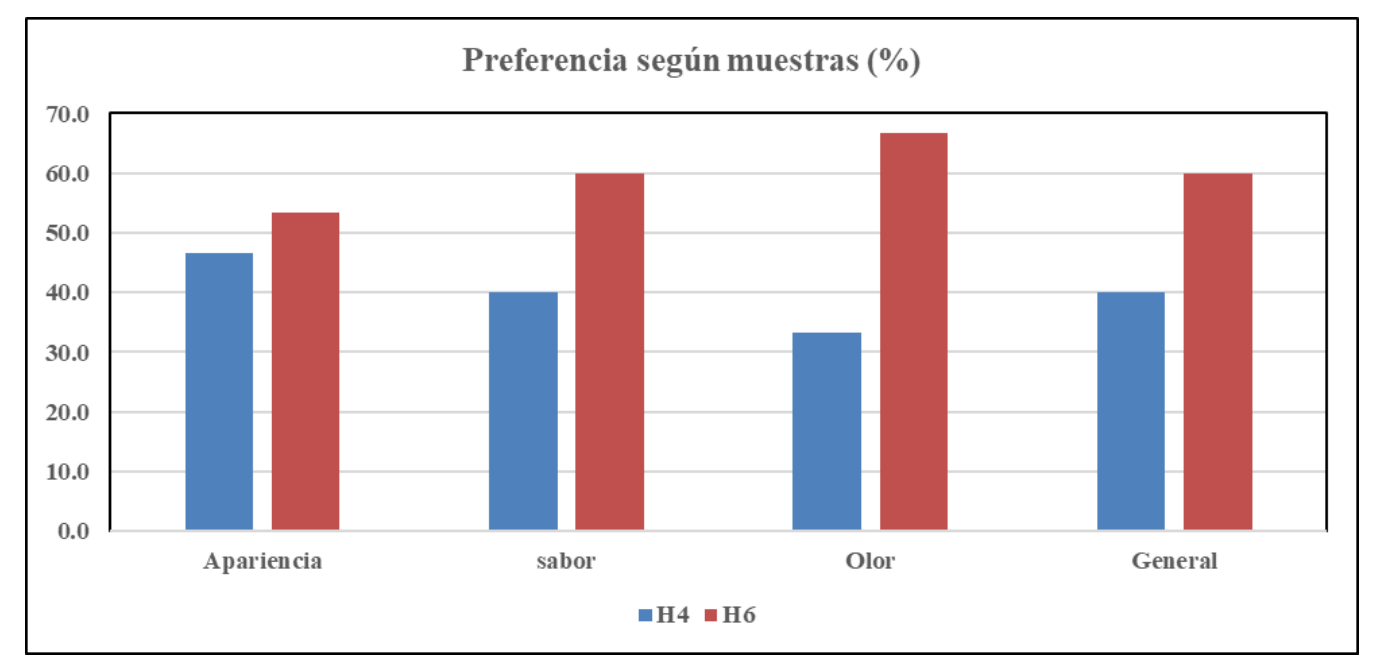

Figura 2. Resultados de la prueba de preferencia de muestras de hidrolizado en polvo.

Tabla 5. Composición química del hidrolizado de anchoveta HG en polvo.

\begin{tabular}{lccc}
\hline \multicolumn{1}{c}{ Ensayo } & \multicolumn{3}{c}{ Resultado \pm desviación estándar } \\
\cline { 2 - 4 } & Experimental & Pandia et al. (2013)* & Sheron et al. (2017) \\
\hline Humedad & $7,01 \pm 0,04$ & - & 10,33 \\
Proteína bruta & $77,13 \pm 0,11$ & 83,30 & 80,51 \\
Grasa cruda & $0,13 \pm 0,07$ & 0,90 & 0,05 \\
Ceniza & $9,33 \pm 0,19$ & 11,60 & 9,11 \\
Carbohidratos & $6,40 \pm 0,46$ & 4,20 & - \\
\hline
\end{tabular}

*Base seca 
El contenido de aminoácidos esenciales del hidrolizado de proteína de anchoveta $\mathrm{HG}$ en polvo (ensayo $\mathrm{H}_{6}$ ) se presenta en la tabla 6. De los valores encontrados, destaca el alto valor de lisina $(10,727$ g/100 g de producto), aminoácido esencial que se encuentra en buena cantidad en las proteínas de origen animal como los derivados de leche, carne y huevos.

Los resultados del análisis microbiológico del hidrolizado de proteína de anchoveta $\mathrm{HG}$ en polvo (ensayo $\mathrm{H}_{6}$ ), se muestran en la tabla 7. Dichos resultados se encontraron muy por debajo de las recomendaciones para consumo humano. Bullón et al, (2018) encontraron una buena aceptabilidad de la proteína hidrolizada de pescado en polvo $(0,4 \mathrm{~g}$ por ración) en las bebidas a base de cereal y pseudocereales (granos andinos) en menores de 6 años.
Por otro lado, el contenido de histamina fue muy bajo (14,91 mg/k de producto), el límite máximo en pescado fresco para consumo humano es $100 \mathrm{mg} / \mathrm{k}$ (SANIPES, 2016). La baja cantidad de histamina en el hidrolizado de proteína de anchoveta en polvo fue atribuida a la adecuada frescura de la materia prima utilizada y las buenas condiciones de proceso en su elaboración. Hleap y Gutiérrez (2017) mencionan que las aplicaciones y usos de un hidrolizado de proteína, con una determinada composición final de péptidos dependerán de la materia prima de donde proviene la proteína, la enzima o enzimas utilizadas, los parámetros de la reacción de hidrólisis y el grado de hidrólisis alcanzado.

Tabla 6. Contenido de aminoácidos esenciales en hidrolizado de anchoveta en polvo.

\begin{tabular}{lc}
\hline \multicolumn{1}{c}{ Aminoácidos ((g de aminoácido/ 100 g de producto) } & Resultado \\
\hline Histidina & 1,654 \\
Fenilalanina + Tirosina & 5,587 \\
Isoleucina & 0,671 \\
Leucina & 2,793 \\
Lisina & 10,727 \\
Metionina & 0,559 \\
Treonina & 0,335 \\
Triptofano & 0,447 \\
Valina & 6,034 \\
\hline
\end{tabular}

Tabla 7. Resultados del Análisis Microbiológico del hidrolizado en polvo.

\begin{tabular}{lc}
\hline \multicolumn{1}{c}{ Ensayo microbiológico } & Resultado \\
\hline N. de Aerobios Mesófilos (UFC/g) & 10 Estimado \\
D de Salmonella sp. (en 25g) & Ausencia \\
N. Staphylococcus aureus (UFC/g) & $<100$ Estimado \\
N. Mohos (UFC/g) & $<10$ Estimado \\
N. Levaduras (UFC/g) & $<10$ Estimado \\
\hline
\end{tabular}

\section{CONCLUSIONES}

Se pudo elaborar un hidrolizado de proteína de anchoveta $\mathrm{HG}$ en polvo de adecuadas características sensoriales, físico-químicas y microbiológicas. El proceso de hidrólisis utilizando primero una endopeptidasa (Protamex) seguido de una exopeptidasa (Flavourzyme 1000L) fue la que presentó el mayor fraccionamiento de la proteína de anchoveta medida a través de ${ }^{\circ} \mathrm{Bx}$ ref. y GH\%. En el hidrolizado de proteína de anchoveta en polvo destacó el alto contenido de lisina, aminoácido esencial de importancia para la nutrición y relacionado con el desarrollo infantil, por lo que el hidrolizado en polvo obtenido podría ser utilizado como fuente de este aminoácido para elaborar productos funcionales que se destinen a los programas sociales de asistencia alimentaria. Es necesario realizar estudios complementarios para mejorar aún más las características sensoriales, evaluar sus cambios en almacenamiento y definir las cantidades y formas de 
uso en los productos funcionales, de preferencia destinados a la población infantil preescolar y escolar.

\section{Conflictos de intereses}

Los autores firmantes del presente trabajo de investigación declaran no tener ningún potencial conflicto de interés personal o económico con otras personas $\mathrm{u}$ organizaciones que puedan influir indebidamente con el presente manuscrito.

\section{Contribuciones de los autores}

Preparación y ejecución: DR, JRO; Desarrollo de la metodología: DR, JRO, AM; Concepción y diseño: DR, JRO; Edición del artículo: DR, JRO. AM; Supervisión del estudio: DR.

\section{REFERENCIAS}

- Accinelli-Tanaka, R., \& López-Oeopeza, L. (2013). Estudio Nutricional y Condición Física de Futbolistas Adolescentes Luego del Consumos de Harina de Pescado como Complemento Nutricional. Rev. Perú. Med. Exp. Salud Publica, 30 (1), 49-53. https://doi.org/10.1590/S172646342013000100010

- ANDINA. Agencia Peruana de Noticias. (2020). Coronavirus consume estos superalimentos para fortalecer tu sistema inmunológico. Disponible en: https://andina.pe/agencia/noticia-coronavirusconsume-estos-superalimentos-para-fortalecer-tusistema-inmunologico-787303.aspx.

- Aldoradín, E., Solari, A., \& Albrecht, M. (2013). Caracterización e hidrólisis enzimática de las pieles de pota (Dosidicus gigas) Bol. invest. Inst. tecnol. Prod. Perú. 11, 59-65.

- Alegre, C. (2015). Análisis Bioinformático de una proteína expresa en el músculo de Engraulis ringens (Anchoveta peruana). Una perspectiva nutricional. Tesis Profesional. Universidad Católica de Santa María. Perú. 113 p. Disponible en: https://1library.co/document/zgwgovvyanalisis-bioinformatico-proteina-musculoengraulis-anchoveta-perspectiva-nutricional.html

- Bullón-Vela V, Valdiviezo G, Baiocchi N, Campos M, Llanos-Cuentas, A., \& Ochoa, TJ. (2018) Aceptabilidad de pre-escolares y escolares a la proteína purificada de pescado en polvo. Rev Peru
Med Exp Salud Publica. 2018;35(2), 234-40. https://doi.org/10.17843/rpmesp.2018.352.3274

- CECOPESCA (Centro Técnico Nacional de Conservación de Productos de la Pesca). (2012). El aprovechamiento de los subproductos de pescado para la obtención de productos funcionales y bioactivos. Madrid: Ministerio de Agricultura, Alimentación y Medio Ambiente. Disponible en http://www.magrama.gob.es/es/pesca/temas/calida d-seguridad alimentaria/06Guia_Subproductos_tcm7-248616_tcm7320453.pdf.

- Dumay, J., Barthomeuf, C., \& Berge, J. (2003). How enzymes may be helpful for upgrading fish by-products: enhancement of fat extraction. J. Aquatic Food Prod. Tech. 13: 69-84. https://doi.org/10.13140/RG.2.1.3781.5760

- García-Moreno, P.G., Guadix, A., Guadix, E.M. \& Charlotte, J. (2016). Physical and Oxidative Stability of Fish Oil-In-Water Emulsions Stabilized with Fish Protein Hydrolysates. Food Chemistry 203:124-135. https://doi.org/10.1016/j.foodchem.2016.02.073

- Garcia, P., Batista, I., Pires, C., Bandarra, N., Espejo, F., Gaudix, A., \& Guadix, E. (2014). Antioxidant activity of protein hydrolysates obtained from discarded Mediterranean fish species. Food Res Int, 65, 469 - 476. https://doi.org/10.1016/j.foores.2014.03.061

- Grillo, J., Gozzer, R., Sueiro, J., \& Riveros, J. (2019). Producción ilegal de harina de pescado en Perú a partir de anchoveta extraida por la flota artesanal y media escala. OCEANA. Lima- Perú. Disponible en: Disponible en: https://peru.oceana.org/sites/default/files/anchovet a_corregido2_0.pdf

- He, S.; Franco, S., \& Zhang, W. (2013). Functions, applications and production of protein hydrolysates from fish processing co-products (FPCP). Food Res Int, $50 \quad$ (1), $289 \quad$ - 297. http://doi.org/10.1016/j.foodres.2012.10.031

- Hleap, J., \& Gutiérrez Cl. (2017) Hidrolizados de pescado - producción, beneficios y nuevos avances en la industria. -Una revisión. Acta Agron.: 66 (3), 311-322. https://doi.org/10.15446/acag.v66n3.52595

- Huss, H (1999). El Pescado fresco: su calidad y cambios de su calidad. Departamento de Pesca. 
FAO (Organización de Naciones Unidas para la Agricultura y Alimentación). Roma.

- KRÜSS Optronic (2020). Informe de aplicación: Refractómetro-medición Brix en la industria de bebidas y zumos. Hamburgo-Alemania. Disponible en:

https://www.kruess.com/documents/Applikationsb erichte/AP130710_001_Medicion_Brix_en_la_in dustria_de_bebidas_ES.pdf

- Maza, S., Aldoradin, E., Pariona, D., Arpi1, D., \& Rosales, M. (2016). Efecto del Desollado y Desangrado de Anchoveta (Engraulis ringens) en Solución de Citrato Sódico. Rev Inv Vet Perú 2016; 27(3): 427-439. https://doi.org/10.15381/rivep.v27i3.12010

- Maza, S., \& Pariona, D. (2020). Mejoramiento del gel de surimi de anchoveta (Engraulis ringens) mediante adición de surimi de brazo de calamar gigante (Dosidicus gigas). Rev Inv Vet Perú; 31(1), e17569. http://dx.doi.org/10.15381/rivep.v31i1.17569

- Morales-Medina, R., Munio, M., Guadix, E.M., \& Camacho, F. (2017). A lumped model of the lipase catalyzed hydrolysis of sardine oil to maximize polyunsaturated fatty acids content in acylglucerols. Food Chemestry 240: 286 - 294. https://doi.org/10.1016/i.foodchem.2017.07.030

- Nguyen, H., Pérez-Gálvez, R., \& Bergé, J. (2012). Effect of diets containing tuna head hydrolysates on the survival and growth of shrimp Penaeus vannamei. Aquaculture, 324 - 325: 127 - 134. http://doi.org/ 10.1016/j.aquaculture.2011.11.014

- Novozymes A/S. (1998). Protamex ${ }^{\mathrm{TM}}$ Product Sheet. B716d-GB, 1:2.

- Oliveira D.A.S.B., Minozzo M.G., Licodiedoff S. \& Waszczynskyj N. (2016). Physicochemical and sensory characterization of refined and deodorized tuna (Thunnus albacares) by-product oil obtained by enzymatic hydrolysis. Food Chem. 207:187194.

https://doi.org/10.1016/j.foodchem.2016.03.069.

- Opheim, M., Šližyte, R., Sterten, H., Provan, F., Larssen, E., \& Kjos, N. (2015). Hydrolysis of Atlantic salmon (Salmo salar) rest raw materials Effect of raw material and processing on composition, nutritional value, and potential bioactive peptides in the hydrolysates. Process
Biochem, $\quad 50 \quad(8), \quad 1247 \quad-\quad 1257$. http://doi.org/10.1016/j.procbio.2015.04.017

- Ordoñez, L.R., \& Hernández, E.M. (2014). Efecto del Proceso de Elaboración de la Conserva "Desmenuzado de Anchoveta" (Engraulis ringens) sobre los Ácidos Grasos Poliinsaturados Omega 3. Ciencia e Investigación 17: 27-32.

- Pandia, S., Solari, A., \& Albrecht, M. (2013). Hidrolizado proteico obtenido a partir de residuos de anchoveta (Engraulis ringens). Evaluación de sus propiedades funcionales Bol. invest. Inst. tecnol. Prod. Perú. 11: 44 - 51.

- Paz, M., Meneses, J.\& López, J. (2016). Digestibilidad de dietas con harina de hidrolizado de pescado, para el levante de arawana (Osteoglossum bicirrhossum) Rev.MVZ Córdoba 21(1):5177-5188. Disponible en: http://www.scielo.org.co/scielo.php?script=sci_ab stract $\&$ pid $=$ S012202682016000100009\&lng=en\&nrm=iso\&tlng=es

- PRODUCE. Ministerio de la Producción (2018). Boletín del sector pesquero. Desenvolvimiento Productivo de la Actividad Pesquera. Lima. Perú. Disponible en: https://ogeiee.produce.gob.pe/index.php/en/shortc ode/oee-documentos-publicaciones/boletinespesca/item/783-2018-enero-boletin-del-sectorpesquero

- PRODUCE. Ministerio de la Producción (2019). Programa Nacional «A Comer Pescado. Disponible en: https://www.acomerpescado.gob.pe/tallasminimas/

- SANIPES. Organismo Nacional de Sanidad Pesquera (2010). Indicadores o Criterios de la Seguridad Alimentaria e Higiene para Alimentos y Piensos de Origen Pesquero y Acuícola. Perú. Disponible en: http://www.sanipes.gob.pe/procedimientos/13_Ma nualIndicadoresocriteriosdeseguridadalimantariarev02-2010.compressed.pdf

- SANIPES. Organismo Nacional de Sanidad Pesquera. (2016). Indicadores Sanitarios y de Inocuidad para los Productos Pesqueros y Acuicolas para Mercado Nacional y de Exportación. Perú. Recuperado de http://www.sanipes.gob.pe/normativas/15_R_DE_ N_057_2016_A1.pdf 
- SAS/STAT (2019). User's guide. SAS Stargraphics. Statistical Analysis System Institute. Cary, NC, USA.

- Sheron, L., Delgado F., Calcino, R., \& Escobar, N. (2017). Concentrado de Proteína a partir de anchoveta (Engraulis ringens) Informe Estudio de Investigación. Universidad Nacional Jorge Basadre Grohmann. Perú.

- Sifuentes-Penagos, G., León, S., \& Castillo, A. (2018). Hidrólisis de las proteínas de anchoveta
(Engraulis ringens) entera por acción de la enzima Protamex $^{\mathrm{TM} .}$ Scientia Agropecuaria: 9 (1); 93-102. https://doi.org/10.17268/sci.agropecu.2018.01.10.

- Vioque, J. \& Millán, F. (2005). Los hidrolizados proteicos en alimentación: suplementos alimenticios de gran calidad funcional $y$ nutricional. Consejo Superior de Investigaciones Científicas. Instituto de la Grasa. Sevilla. España. Disponible

en:http://digital.csic.es/bitstream/10261/5750/1/IG _AGROCSIC_2.pdf. 